\title{
COMPARISON OF UPPER LIP BITE TEST WITH MODIFIED MALLAMPATI TEST AND THYROMENTAL DISTANCE FOR PREDICTING DIFFICULTY IN ENDOTRACHEAL INTUBATION- A PROSPECTIVE STUDY
}

\author{
Ch. Srinivas Rao1, T. Ranganath², S. Phani Bhushan Rao 3 , K. Sujani ${ }^{4}$ \\ ${ }_{1}^{1}$ Associate Professor, Department of Anaesthesiology, Rajiv Gandhi Institute of Medical Sciences, Srikakulam. \\ ${ }^{2}$ Assistant Professor, Department of Anaesthesiology, Rajiv Gandhi Institute of Medical Sciences, Srikakulam. \\ ${ }^{3}$ Senior Resident, Department of Anaesthesiology, Rajiv Gandhi Institute of Medical Sciences, Srikakulam. \\ ${ }^{4}$ Registrar, My Cure Hospitals, Visakhapatnam.
}

\section{ABSTRACT}

\section{BACKGROUND}

There are many tests to predict difficult intubation viz., Patil's measurement of Thyromental Distance, the Mallampati Test and the Wilson Scoring System, but these tests have been shown to have high false positive rates which detract their usefulness. ${ }^{1,2}$

The aim of this study is to compare the sensitivity, specificity, positive predictive value and negative predictive value of Upper Lip Bite Test with Modified Mallampati Test and Thyromental Distance in predicting difficult intubation.

\section{MATERIALS AND METHODS}

Two hundred patients between 16 -65 years of age of either sex undergoing elective surgical procedures under general anaesthesia were enrolled in the study. Pre-operative evaluation of airway was done by Modified Mallampati Test, Upper Lip Bite Test and Thyromental Distance. Modified Mallampati Test grade III and IV, Upper Lip Bite Test class III \& TMD $<6.5 \mathrm{~cm}$ were considered as predictors of difficult intubation. On the day of surgery, patients were pre-medicated with Inj. Glycopyrrolate $0.005 \mathrm{mg} / \mathrm{kg}$ IV, Inj. Midazolam $0.05 \mathrm{mg} / \mathrm{kg} \mathrm{IV}$, and Inj. Fentanyl $2 \mu \mathrm{g} / \mathrm{kg}$ IV. Patients were pre-oxygenated with 100\% oxygen, induced with Inj. Thiopentone $5 \mathrm{mg} / \mathrm{kg}$ IV and intubation was facilitated by Inj. Suxamethonium 1-2 mg/kg IV. Laryngoscopy was done in sniffing position, glottic views were graded according to the Cormack and Lehane classification. Patients of Cormack- Lehane grade III/IV were considered as difficult to intubate. TMD was measured using tape in centimetre.

\section{RESULTS}

In the present study, the sensitivity, specificity, positive predictive value and negative predictive value of Modified Mallampati test were $60 \%, 97.89 \%, 60 \%$ and $97.89 \%$ respectively. The sensitivity, specificity, positive predictive value and negative predictive value of Upper Lip Bite Test were 30\%, 97.4\%, 37.5\% and 96.35\% respectively. Also, the sensitivity, specificity, positive predictive value and negative predictive value of Thyromental Distance were 10\%, 97.4\%, 16.67\% and 95.36\% respectively.

\section{CONCLUSION}

Modified Mallampati Test has high sensitivity, specificity, positive and negative predictive values compared to Upper Lip Bite Test and Thyromental Distance test. So, it can be used as a simple bedside screening test for difficult intubation along with other tests. Upper Lip Bite Test is more accurate than Thyromental Distance and probably second most important test in prediction of difficult airway.

\section{KEYWORDS}

Upper Lip Bite Test, Modified Mallampati Test, Thyromental Distance, Difficult Intubation.

HOW TO CITE THIS ARTICLE: Rao CS, Ranganath T, Rao SPB, et al. Comparison of upper lip bite test with modified Mallampati test and thyromental distance for predicting difficulty in endotracheal intubation- A prospective study. J. Evolution Med. Dent. Sci. 2017;6(18):1413-1416, DOI: 10.14260/Jemds/2017/309

\section{BACKGROUND}

In day-to-day practice, Modified Mallampati Test (MMT) and Thyromental Distance (TMD) are used to predict the difficult endotracheal intubation, whereas Upper Lip Bite Test (ULBT) is not as popular as that. Hence, this study was proposed to compare Upper Lip Bite Test with Modified Mallampati Test

Financial or Other, Competing Interest: None.

Submission 23-01-2017, Peer Review 17-02-2017,

Acceptance 22-02-2017, Published 02-03-2017.

Corresponding Author:

Dr. Ch. Srinivas Rao

Flat No. 4G, Rednam Alcazar

Opposite SBI, Old Jail Road,

Visakhapatnam-530002,

Andhra Pradesh.

E-mail: srinivasrao719@gmail.com

DOI: $10.14260 /$ jemds $/ 2017 / 309$

and Thyromental Distance in patients who are undergoing elective surgery under general anaesthesia.

\section{MATERIALS AND METHODS}

After obtaining institutional ethical committee clearance and written informed consent, the present study was conducted in 200 patients aged between 16 years and 65 years of either sex with ASA physical status I \& II who were scheduled for elective surgeries under general anaesthesia at King George Hospital, Andhra Medical College, Visakhapatnam in the Department of Anaesthesiology.

Patients who are unable to open the mouth, with cervical spine fractures and deformities, upper airway tumours, loose incisors, who underwent lip surgeries and edentulous were excluded.

Pre-operatively each of the patient's airway was evaluated using MMT, TMD and ULBT. 
TMD was measured using tape in centimetre.

Classification of oropharyngeal view was done according to MMT, wherein the patients were placed in sitting position with mouth fully open and tongue maximally protruded, and patients were asked not to phonate with the examiner sitting in front of the patient in line with the face.

Class I - Soft palate, fauces, uvula and pillars.

Class II - Soft palate, fauces and uvula are seen.

Class III - Soft palate and base of uvula.

Class IV - Soft palate not visible.

In the ULBT, patients were asked to bite their upper lip with lower incisors and were graded accordingly-

Class I- Lower incisors can bite upper lip above the vermillion line.

Class II- Lower incisors can bite upper lip below the vermillion line.

Class III- Lower incisors cannot bite the upper lip.

\section{TMD (Patil's Test)}

Thyromental Distance is measured from tip of thyroid cartilage to inside of mentum in a fully extended neck with closed mouth.

Grade $1=>6.5 \mathrm{~cm}$ - No problem with laryngoscopy \& intubation.

Grade $2=6-6.5 \mathrm{~cm}$ - Difficult laryngoscopy but possible.

Grade $3=<6 \mathrm{~cm}$ - Laryngoscopy may be impossible.

On the day of surgery, IV line was secured prior to surgery in the pre-operative room, once the patient was shifted to the operating theatre, patients were monitored with electrocardiogram, non-invasive blood pressure and pulse oximeter.

Patients were pre-medicated with Inj. Glycopyrrolate $0.005 \mathrm{mg} \mathrm{kg}^{-1} \mathrm{IV}$, Inj. Midazolam $0.05 \mathrm{mg} \mathrm{kg}^{-1} \mathrm{IV}$, Inj. Fentanyl $2 \mathrm{mcg} \mathrm{kg}^{-1}$. After pre-oxygenation with $100 \%$ oxygen for 5 minutes, patients were induced with Inj. Thiopentone $5 \mathrm{mg}$ $\mathrm{kg}^{-1}$ IV and the endotracheal intubation was facilitated with Inj. Suxamethonium 1.5 to $2 \mathrm{mg} \mathrm{kg}^{-1} \mathrm{IV}$ by a senior Anaesthesiologist having minimum five years of experience in clinical anaesthesia.

The patient's head and neck were kept in sniffing position, laryngoscopy was done using appropriate sized Macintosh blade and glottic view was graded according to the Cormack Lehane scale.

Grade I- Full view of the glottis.

Grade II- Only posterior commissure visible.

Grade III- Only tip of epiglottis visible.

Grade IV- No glottic structure visible.

Patients were intubated with appropriate sized endotracheal tube. Vitals were monitored throughout the procedure. At the end of surgery, patients were adequately reversed with Inj. Glycopyrrolate $0.01 \mathrm{mg} / \mathrm{kg}$ and Inj. Neostigmine $0.05 \mathrm{mg} / \mathrm{kg}$ IV and extubated after thorough oral suctioning. After stabilisation, patients were shifted to postoperative recovery room.

\section{Statistical Analysis}

The pre-operative airway assessment data and the findings during intubation were used to determine the sensitivity, specificity, positive and negative predictive value for each test.
Fisher exact test and McNemar's test were used to calculate statistically significant difference in sensitivity and specificity between these tests respectively.

\section{Statistical Terms}

\section{True Positive}

A difficult intubation that had been predicted to be difficult.

False Positive

An easy intubation that had been predicted to be difficult.

\section{True Negative}

An easy intubation that had been predicted to be easy.

\section{False Negative}

A difficult intubation that had been predicted to be easy.

\section{Sensitivity}

The percentage of correctly predicted difficult intubations as a proportion of all intubations that were truly difficult, i.e., true positives/(true positive + false negatives).

\section{Specificity}

The percentage of correctly predicted easy intubations as a proportion of all predicted difficult intubations, i.e., true negative/(true negative + false positives).

\section{Positive Predictive Value (PPV)}

The percentage of correctly predicted difficult intubations as a proportion of all predicted difficult intubations, i.e., true positive/(true positive + false positives)

\section{Negative Predictive Value (NPV)}

The percentage of correctly predicted easy intubations as a proportion of all predicted easy intubations, i.e., true negatives/(true negatives + false negatives).

\section{RESULTS}

\begin{tabular}{|c|c|c|}
\hline 1 & Sex (M: F) & $110: 90$ \\
\hline 2 & Age (Mean) & 44.93 years \\
\hline 3 & BMI (n=200) & $23.86 \mathrm{~kg} / \mathrm{m}^{2}$ \\
\hline \multicolumn{3}{|c|}{ Table 1. Demographic Data } \\
\hline
\end{tabular}

\begin{tabular}{|c|c|c|c|}
\hline & \multicolumn{2}{|c|}{ Cormack-Lehane } & \multirow[b]{2}{*}{ Total } \\
\hline & $\begin{array}{l}\text { Grade } \\
\text { I and II }\end{array}$ & $\begin{array}{l}\text { Grade } \\
\text { III and IV }\end{array}$ & \\
\hline Modified Mallampati I, II & 186 & 4 & 190 \\
\hline Modified Mallampati III, IV & 4 & 6 & 10 \\
\hline
\end{tabular}

Table 2. Relation between Modified Mallampati test and Laryngoscopic View

\begin{tabular}{|c|c|c|c|}
\hline \multirow{2}{*}{} & \multicolumn{2}{|c|}{ Cormack-Lehane } & \multirow{2}{*}{ Total } \\
\cline { 2 - 3 } & $\begin{array}{c}\text { Grade } \\
\text { I and II }\end{array}$ & $\begin{array}{c}\text { Grade } \\
\text { III and IV }\end{array}$ & \\
\hline ULBT I ,II & 187 & 5 & 192 \\
\hline ULBT III & 5 & 3 & 8 \\
\hline Table 3. Relationship between Upper & \\
Lip Bite Test (ULBT) and Laryngoscopic View \\
\hline
\end{tabular}




\begin{tabular}{|c|c|c|c|}
\hline & \multicolumn{2}{|c|}{ Cormack-Lehane } & \multirow{2}{*}{ Total } \\
\cline { 1 - 3 } & Grade I and II & Grade III and IV & \\
\hline TMD $>6.5 \mathrm{~cm}$ & 189 & 5 & 194 \\
\hline TMD $<6.5 \mathrm{~cm}$ & 5 & 1 & 6 \\
\hline \multicolumn{2}{|c|}{$\begin{array}{r}\text { Table 4. Relationship between Thyromental } \\
\text { Distance (TMD) and Laryngoscopic View }\end{array}$} \\
\hline
\end{tabular}

\begin{tabular}{|c|c|c|c|}
\hline Statistical terms & MMT & ULBT & TMD \\
\hline True positive & 06 & 03 & 01 \\
\hline False positive & 04 & 05 & 05 \\
\hline True negative & 186 & 185 & 185 \\
\hline False negative & 04 & 07 & 09 \\
\hline Sensitivity & $60 \%$ & $30 \%$ & $10 \%$ \\
\hline Specificity & $97.89 \%$ & $97.4 \%$ & $97.4 \%$ \\
\hline Positive predictive value & $60 \%$ & $37.5 \%$ & $16.67 \%$ \\
\hline Negative predictive value & $97.89 \%$ & $96.35 \%$ & $95.36 \%$ \\
\hline Table 5. Comparison between the Three Predicting Tests \\
\hline
\end{tabular}

\section{DISCUSSION}

The demographic characteristics in the present study were comparable to studies done by Krobbuaban ${ }^{3}$ et al and Krishna ${ }^{4}$ et al.

In the present study, incidence of difficult intubation was found to be $5 \%$ (ten cases of difficult intubation out of two hundred patients) which is comparable to the results obtained by Frerk and Savva.5,6

Out of these 10 cases, 3 cases were intubated with the help of a stylet and remaining 7 cases were intubated with the help of a bougie.

There were no cases of failed intubation in this study.

In the present study, sensitivity of Modified Mallampati Test. (MMT) was found to be $60 \%$ which is comparable to the study conducted by M. Atif et al (60.7\%). ${ }^{7}$

The specificity of MMT in current study was $97.89 \%$ which is more than that of Khan ${ }^{8}$ et al (66.8\%) and Eberhart 9 et al (61\%). A higher specificity similar to our study has also been reported by Cattano et al. ${ }^{10}$

The PPV of MMT in the current study was $60 \%$ which is quite high when compared to other studies. This can be explained by the fact that all the patients were evaluated by a single resident reducing the inter-observer variability and a senior anaesthesiologist doing the laryngoscopy.

The NPV (97.89\%) of MMT in the present study was comparable to the studies conducted by Khan $\mathrm{ZH} 8$ et al (98.4\%), Eberhart ${ }^{9}$ et al (93.8\%) and Atif 7 M et al (96.6\%).

Khan $\mathrm{ZH}^{3}$ introduced the Upper Lip bite test (ULBT) in 2003 which evaluates the patient's ability to reach or completely cover the upper lip with lower incisors. Since the range and freedom of mandibular movement and the architecture of the teeth have pivotal roles facilitating laryngoscopic intubation, the upper lip bite test could serve as a good predictor for difficult laryngoscopic intubation.

The sensitivity of ULBT in our study was $30 \%$ which is well below what $\mathrm{Khan}^{8}$ et al had got in their study (76.5\%), but it was nearer to the value obtained by Eberhart ${ }^{9}$ et al (28\%). Lower sensitivity of the ULBT can be explained due to low incidence of ULBT class III in our study.

The specificity of ULBT in present study was $97.4 \%$ well above the original trial by Khan $\mathrm{ZH}^{8}$ et al (88.7\%) \& Eberhart ${ }^{9}$ et al (92.5\%). This is because of the lesser number of false negative results obtained in our study with ULBT.
The PPV of ULBT in current study was $37.5 \%$ which is

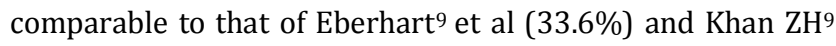
et al (28.9\%) studies.

The NPV of ULBT was $96.35 \%$ which is comparable to original study by Khan $\mathrm{ZH}^{3}$ et al (98.4\%), Eberhart ${ }^{9}$ et al (90.6\%) and Atif7 et al (94.5\%). Though it is statistically significant $(\mathrm{p}<0.05)$, has a very poor sensitivity making it an unreliable test to screen the patients for difficult intubation.

Patil originally suggested that in a normal adult, the Thyromental Distance (TMD) is greater than $6.5 \mathrm{~cm}$ and this cut-off point is now commonly applied.

The sensitivity of TMD test was $10 \%$ in our study. This is less compared to that of Freda Richa ${ }^{11}$ et al, $(21.8 \%)$ which might be because of incorrect evaluation of the measurement from inner or outer mentum.

The specificity of TMD in the present study was $97.4 \%$ which was similar to the studies conducted by Salimi A et al 12 (93.3\%) and A K Gupta et $\mathrm{al}^{13}$ (96.5\%).

The positive predictive value of TMD in our study was $16.67 \%$ which was almost comparable to that of Salimi A et al $^{12}(22 \%)$. The negative predictive value of TMD was $95.36 \%$ which is comparable to the study done by Freda Richa et al (94\%). ${ }^{6}$

On comparing these three tests, MMT was (60\%) found to be more sensitive than ULBT (30\%) and TMD (10\%), although these tests had high specificity and NPV. Difference in the sensitivity between these three tests was found to be statistically significant.

The ULBT has higher specificity (97.4\%) which is statistically significant $(\mathrm{p}<0.05)$. Also, it has a very poor sensitivity making it an unreliable test to screen the patients for difficult intubations.

There are certain disappointing results in the present study in validation of difficult airway e.g., a Cormack-Lehane grade III that could easily be transferred into a grade II or better by applying external pressure to the larynx (BURP manoeuvre) or other simple techniques, because these patients would not have been described to be difficult.

All these three tests have a negative predictive value more than $90 \%$, thus stressing the fact that they can be good predictors of easy intubation, rather as positive predictors of difficult intubation.

\section{CONCLUSION}

1. MMT has high sensitivity, specificity, PPV \& NPV compared to the other two tests. So, it can be used as a simple bedside screening test for difficult laryngoscopy combined with other tests.

2. ULBT is more accurate than TMD and probably the $2^{\text {nd }}$ most important test in prediction of difficult airway.

3. In spite of various airway assessment tests, no single test is $100 \%$ accurate. Therefore, it is advisable to use combination of different tests or use various scoring systems for predicting difficult intubation.

\section{REFERENCES}

[1] Wilson ME, Spiegelhalter D, Robertson JA, et al. Predicting difficult intubation. $\mathrm{Br} \mathrm{J}$ Anaesth 1988;61(2):211-6.

[2] Charters P, Perera S, Horton WA. Visibility of pharyngeal structures as a predictor of difficult intubation. Anaesthesia 1987;42(10):1115. 
[3] Krobbuaban B, Diregpoke S, Kumkeaw S, et al. The predictive value of the height ratio and thyromental distance: four predictive tests for difficult laryngoscopy. Anesth Analg 2005;101(5):1542-5.

[4] Krishna HM, Agarwal M, Dali JS, et al. Prediction of difficult laryngoscopy in Indian population: role of ratio of patient's height to thyromental distance. J Anaesth Clin Pharmacol 2005;21(3):257-60.

[5] Savva D. Prediction of difficult tracheal intubation. Br J Anaesth 1994;73(2):149-53.

[6] Ramadhani SAL, Mohamed LA, Rocke DA, et al. Sternomental distance as sole predictor of difficult laryngoscopy in obstetric anaesthesia. $\mathrm{Br} J$ Anaesth 1996;77(3):312-6.

[7] Atif M, Abdullah M, Yusuf M. Accuracy of upper lip bite test. Professional medical journal 2013;20(1):132-8.

[8] Khan ZH, Kashfi A, Ebrahimkhani E. A comparison of the upper lip bite test (a simple new technique) with modified Mallampati classification in predicting difficulty in endotracheal intubation: a prospective blinded study. Anesth Analg 2003;96(2):595-9.
[9] Eberhart LH, Arndt C, Cierpka T, et al. The reliability and validity of the upper lip bite test with the Mallampati classification to predict difficult laryngoscopy: an external prospective evaluation. Anesth Analg 2005;101(1):284-9.

[10] Cattano D, Panicucci E, Paolichhi A, et al. Risk factors assessment of the difficult airway: an Italian survey of 1956 patients. Anesth Analg 2004;99(6):1774-9.

[11] Richa F, Yazbeck P, Yazigi A, et al. Value of the association of the upper lip bite test (ULBT) with other tests in predicting difficulty of endotracheal intubation. Anaesthesiology 2005;103:A1418.

[12] Salimi A, Farzanegan B, Rastegarpour A. Comparison of the upper lip bite test with measurement of thyromental distance for prediction of difficult intubations. Acta Anaesthesiology Taiwan 2008;46(2):61-5.

[13] Gupta AKR, Ommid M, Nengroo S, et al. Predictors of difficult intubation: study in Kashmiri population. BJMP 2010;3(1):307. 